\title{
Work-Life Reconciliation Policies From Well-Being To Development: Rethinking EU Gender Mainstreaming
}

\author{
M.R. Garofalo, University of Salerno \\ garofalo@unisa.it \\ M. Marra, CNR-University of Salerno \\ mita.marra@issm.cnr.it
}

\begin{abstract}
Across the European Union (EU), gender policies are cross-cutting initiatives incorporated within the major axes of regional operational programs, and specifically, within active labormarket, local development and inclusion policies. This is the so-called gender mainstreaming across EU Structural Funds, calling for increasing policy instruments integration. The aim of this paper is to understand if and how to improve women's well-being and subsequently participation in collective action through reconciliation policies. These measures aim to allow women and men to choose how they can reconcile family care, paid work, career advancement, and leisure. The idea is that such a choice implies a time allocation pattern, which is not exclusively determined by market mechanisms and/or policy measures, but also by cultural trajectories, moral values, intrinsic motivations and rules (Folbre, Nelson 2002; North, 2005; Witt 2003), varying across regions and within groups. Furthermore, the outcomes of this choice are not completely internalized as individual well-being but they can also create positive externalities.

First, this paper reconstructs reconciliation policies and their governance structures across less-developed regions in Italy (so-called EU Objective 1 areas) within the EU programming phase 2000-2006. Drawing upon this reconstruction, out analysis seeks to account for differences in both contextual conditions and individual characteristics, which, in turn, shape regional development processes. Second, the paper focuses on the design of conciliation policies to unveil what underlying microeconomic premises explain the expected beneficiaries' behavioural change. Departing from the inadequacy of standard economics, whereby work-life reconciliation would be reduced to a unique choice pattern at the individual level, the paper examines those factors of subjective identities and contextual characteristics that actually affect work-life reconciliation choices, and by this way they can have a development impact (Bowles 1998, Ray, 2000, Sen 1999).

In fact, the traditional public choice approach to gender policy may not only perpetuate a male-dominated structure of socioeconomic relations but it may also keep the economy working at a less efficient level. In other words, reconciliation policies may end up reinforcing a path dependent equilibrium of low efficiency, accentuating institutional, economic, social, and cultural traps (Bowles, Durlauf and Hoff 2006). By contrast, our idea is that reconciliation policies can work as development policies as long as they alter current power structures and enhance women capabilities. Building upon this critical review of the existing gender policy framework, we put forward a cognitive framework for work-life reconciliation as a driving force to development.
\end{abstract}

Key words: Microeconomic behaviour; Gender Mainstreaming; Intrinsic Motivations; Local Development; Conciliation; Power Structures

JEL classification: D01; O17; J16 


\section{Introduction}

In Italy, work-life reconciliation policy has gained prominence within the context of the European social model and the institutional framework governing the implementation thereof, based on a system of formal competences at various decision-making levels. It is well-known that the European social model was originated by the European Employment Strategy (hereinafter EES) (1997), reaffirmed at the European Council of Lisbon (2000) and re-launched during the European Council of Barcelona (2002). As for the institutional framework for its implementation, it is defined by the Open Method of Coordination (hereinafter OMC), first applied specifically to employment, then also to welfare policies. The EES was based on some supply-side intervention guidelines of "minimum resistance," based on four key pillars: adaptability, entrepreneurship, employability and equal opportunities. At that time, in the then prevailing typically liberalist view (Jackman 1998), the major concern seemed to be the creation of opportunities of access to the labour market for the disadvantaged (young people, women, the long-term unemployed), who could thus increase their chances of employment, as well as the promotion of small and medium enterprises and entrepreneurship. The limit of this strategy was that it did not fully address the issue of structural reforms and did not provide indications as to the productive sectors that had the potential to relaunch the Italian economy and consequently increase employment.

Lisbon and Barcelona strategies have asserted the principle that the achievement of the employability target cannot be considered only in quantitative terms, but have to focus specifically on the quality of work: the key innovation consisted in linking employment targets to development targets, and in supporting an integrated approach to those policies that contributed to improving the standard of living, and, ex ante, the opportunities of choice for people overall, as well as from an egalitarian perspective. Policies of social inclusion and equal opportunities act as a go-between for employment and development. The OMC, on the one hand, defines the common targets and the admittance criteria to the ESF at European level; on the other, it delegates to the Member States the burden of reforming the national institutions' structure and of defining the implementation procedures of the guidelines by compiling the National Action Plans (NAP) ${ }^{1}$

The wide and multi-disciplinary literature written on both the policy overall framework and its institutional system, as well as on each incentive measure, can be classified according to three categories: (i) integration, (ii) cohesion, and (iii) convergence. This literature tends to consider aggregate values as indicators of performance and of success of a specific policy or measure, often from the perspective of comparative analysis. In the case of our study, the existing literature refers, for instance, to fertility rate and female participation in the labour market, highlighting the Italian anomaly. That is, differently from other developed countries, in the 1990s, Italy has presented a direct relationship between a low birth rate and a low rate of female employment (Simonazzi 2006), showing crowding-out effects of policy targets, e.g. between increase in employment and in occupational segregation, or between increase in employment and indirect discrimination.

These research findings suggest that work-life reconciliation experiences reveal that women condition is - we would say - an intrinsically unstable category (Barker 2005), precisely because it is a heuristics of difference and, therefore, of the incompleteness of the historical process aimed at reaching inclusion and equal opportunities (Sartori 2005). The instability of the "women condition" category explains the occurrence of (i) crowding-out effects in policy targets that improve some women's lives at the expense of others, and thus (ii) the onset of differences and power within gender relations, basically concerning the position in the labour market, the fairness of the "cooperative conflict" within the family, forms of violence and deprivation (Sen 2003) and, with reference to the most recent feminist theory, forms of representation and identity (Robeyns 2000). Although it is beyond the scope of the present study to review this empirical literature, this paper

\footnotetext{
${ }^{1}$ Many are the EU Communications supporting the integrated approach to policies; COM (2000) 379, Social Policy Agenda, Bruxelles; COM (2001) 264, A Sustainable Europe For A Better World: A European Union Strategy For Sustainable Development, Bruxelles
} 
shares, and adopts this view, focussing on women's reconciliation equilibria in marginalised conditions, due to either subjective characteristics or the economic context ${ }^{2}$ : even if the institutional system and the policy strategy are identical, women's conditions could be different given a different treatment.

Indeed, the integrated approach to policies calls us to focus on the interpretative level, from the formal framework to the real process of policy making, from the aggregate value and the relationship between aggregate values to the conditions allowing or preventing, depending on the case, changes in the microeconomic behavioural patterns, in the nature of the interactions, and the possible activation of new markets and of agglomeration and external effects. Of the three dimensions characterising policy integration, that is, (i) the institutional actors sitting at the planning table, (ii) the financial resources and the measures and incentives adopted in favour of a single individual, depending on the different context of choice in which (s)he lies (within the family, in employment, in welfare relations, in a collective action), it is the latter which allows us to shift the attention on the beneficiary. This involves reversing the methodological approach in favour of an inductive one, collecting as much information as possible on the individual and contextual characteristics, on the beneficiary's standard of life and on the nature of his/her interactions. At the theoretical level, the integrated approach to policies can be unpacked through the lens of the approach to capabilities, but only provided that capabilities individualism is intended not as ontological individualism, but as ethical individualism (Robeyns 2003, Dreze and Sen 1995). Among the various possible interpretations, "ethical individualism" is referred to as an "embedded individual" (Ballett et al. 2007), who is merely interested in belonging to a context and in the values and nature of his/her interactions ${ }^{3}$.

With the aim to build a cognitive framework, we have undertaken different steps. First, we have come across with a considerable body of empirical studies on women conditions. These studies suggest that although there is a well established gender friendly policy approach throughout Europe, policy outcomes vary significantly, thus there emerge different stories about reconciliation.

Second, we have empirically explored how this broadly shared policy approach has been perceived and acted upon by two different purposeful samples, namely: (i) heterogeneous groups of women (by age, education, occupation, gender-related experience), who have self-selected for participating in reiterated formal training offerings to promote gender political representation, and (ii) a number of key informants involved in gender-related decision making (policy makers at the regional and local level, managers within public, private, and social sector, entrepreneurs, and representatives of unions, experts in counselling and legal issues). Through class discussion and formal testing, the first sample has provided the raw material for understanding the crucial issues affecting work-life reconciliation, while through in depth-interviewing and focus group analysis, the second sample has highlighted those relevant and controversial aspects handled by current regional gender friendly policies ${ }^{4}$.

Third, we have critically built a taxonomy and proposed a reflection on the integrated approach to policies, including gender policies, with the aim to suggest a cognitive framework, enabling us to interpret not only how the policy design (favouring work-life reconciliation) modifies the individual's room for choice, or how many people benefit from the policy. Most importantly, this cognitive approach allows us to gain insights on how psychological and cognitive factors, roles and power in the various interactions change and differentiate the ability to perceive, select, and exploit the benefits a policy may offer. And, if these benefits do manifest, what are the main factors explaining beneficiaries' different reactions to them? How important is the initial context? Which are the macro implications that may be derived from the change in the micro behaviour induced by the policy?

\footnotetext{
${ }^{2}$ See Sen (1999) by which the life expectancy of black women in Usa is comparable with that of women in India.

${ }^{3}$ See the recent literature on Smith's idea of moral sentiments as our guide in economic actions, see Gintis et al. eds, 2005.

${ }^{4}$ For the interview and questionaire's protocols, see Appendix.
} 
The paper is organized as follows. Section one illustrates the need for the cognitive framework, outlining also the methodological approach, namely, the evolutionary approach (Bowles 2002, Dopfer et al. 2004,Witt, 2003). Section two reviews the literature employed, with specific reference to the theory of development, according to which it is assumed that initial conditions count, but they may be anyway modified through the optimistic expectations of those economic agents inclined to change (Ray, 1998). Section three critically reconstructs the whole set of policy initiatives addressing gender equality, which may have a bearing on work-life reconciliation choices. Section four turns to analyzing those factors affecting work-life reconciliation across EU economically lagging regions in Italy to gain insights on its impact on processes of economic development. Finally, bridging poverty traps and aspirations change models, section five highlights how our evolutionary cognitive framework enables us to disentangle the two ways chain connecting women's aspiration building and economic development, as a new set of policies and rules emerges at the meso level. In other terms, reconciliation of work and private life becomes a socially built category overcoming the standard economic dichotomy between private and public domains. The extent to which positive externalities within specific groups or sectors in the economy arise, work-life reconciliation paves the way to differences-valuing development paths.

\section{How Many Stories About Reconciliation Policy! Building A Cognitive Framework}

Mainstreaming and empowerment of gender policies represent an important innovation within the most recent European debate, as they place gender questions at the heart of the integrated approach to policies. However, one thing is to assert the principle's relevance, another is to act on the material and cognitive conditions that make this principle relevant in the different local and social contexts, and especially crucial in both public and private decisional behaviours. In other words, one thing is to consider mainstreaming and empowerment in the short term, when they innovate the pre-existing framework of sectorial policies, another thing is to try and monitor, in the medium term, if and how the behaviour of public and private decision-makers (which is a "rule following" behaviour with respect to mainstreaming and empowerment) can activate a process of change and modify the pattern of development, having modified the system of rules presiding over the productive allocation of the resources and the distribution of the relative benefits.

Compared with the political-institutional context outlined so far, and with reference to the mainstreaming and empowerment of gender policies, the measures favouring work-life reconciliation may be read according to different theoretical perspectives, leading to alternative policy results. A first perspective is that wherein the innovative character of a policy measure - as a new formal rule - gets levelled like a supply-side measure, and is only effective insofar as it modifies the conditions of choice of those subjects that could already (given for instance their power distribution and employment position, their cultural and professional background, their set of values, their family's structure and income, the local context, etc.) take advantage of that policy in negotiating their employment relation. A second perspective is that wherein the introduction of a new law or incentive measure can ignite a process of change, achieving the expected benefits, but only provided that two conditions occur: (i) the microeconomic change of an employer-employee relation produces agglomeration effects on the local labour market, differentiates and enlarges transactions on other markets (e.g. new demand for higher education, own free time, offer of time for voluntary work and collective actions) and within family relationships (Boserup 1970, Sen 2003): this is the argument of policy sustainability, realised by the threshold effect; (ii) the change in the context - as seen in (i) - activates a process of change of the preferences, the perception of the opportunities and the nature of the interactions (of power), so that the equilibrium solutions that the new law/policy measure had made possible in the "work-life" choice retroact on the system of individual preferences. 
Even if this process can apply in general to all the subjects identified as the targets of the law/policy, what actually influences the microeconomic decisions also takes into consideration the positions occupied by the potential targets of such law/policy. This may be conceptualised as a twochain relation, the effects of which are not unique and deterministic, but multiple: what counts is the agents' positions and aspirations, which matter in context and - depending on their changeability activate agglomeration effects and vice versa (Ranis et al. 2004).

Why is it necessary for us economists to suggest a cognitive framework to interpret the work-life reconciliation policy? What difference does it make whether this policy is conceived as a real time process (Dixit 1996) in its “emergence/adoption/adaptation and change" phases (Dopfer et al., 2004), or rather, as usual, as a formal design of the institutional rulers, aims and resources, according to the vertical subsidiarity? What difference does it make whether it is applied to the EU Obj.1 regions, for instance for the weight of the 10+ year long history of Structural Funds that, depending on the case, encouraged or discouraged public decision-makers to conform to the new rule and private decision-makers to perceive and take advantage of the new rule or of policy benefits, facing the risk of innovation instead of keeping a rent-seeking behaviour?

Among the many answers to these preliminary questions, we have selected two answers belonging to the broadly debated policy evaluation approach, and one specifically related to women's conditions, as recently emerging from the feminist perspective (Feminist Economics 1999 and 2003).

- First answer: Building upon the realist policy analysis and evaluation (Pawson and Tilly 1997, Pawson 2001), since "many and different stories" may be told about a policy ${ }^{5}$, they can only be accepted as explanations if coherent with the "ideological view" and the selection of facts, assumed to be a good representation of individuals/population/area, the target of that policy. A cognitive framework is therefore necessary to make the different stories comparable and to improve the explanatory power of economics: the theoretical level becomes explicitly instrumental to the decisional one. Furthermore, the multiple "stories about a policy" are particularly crucial in our case since, as we shall see in detail in section three, women conditions are differentiated across and within gender and because, as mentioned earlier, their key features have shifted recently from matters of material deprivations to forms of cultural and linguistic representation, while differences in power remain significant as well as their ethical implications.

- Second answer: The achievement of the ultimate aim of a policy, as negotiated at the strategic level (i.e. the enlargement of the opportunities of choice through the redistribution of decisional power does not correspond to the purchasing power), does not uniquely depend on a specific measure, in our case Art. 9 of Law n. 53/2000. It rather builds on: (i) how this policy aim fits into other measures and policies (e.g. development, welfare, labour, equal opportunities policies), so that the individual equilibrium solution depends on the actual possibility of making alternative lifelong choices compatible (Villa 2006), and (ii) who and how many the beneficiaries are. Thus, a policy story concerns both the content of the newly introduced entitlement, and the criteria for its eligibility, i.e., how reconciliation redistributes power along the short side of the labour market, considering whether peculiarities in the (for profit and non-for profit) private and public sector exist. This also relates to how and for whom eligibility conditions modify bargaining power as well as the objectives of the weak subject within the family (gendered role division and sharing, right to higher education, free time as a luxury good), in relation to public institutions (access conditions to health services, quality of services, minimum wage, parenting support), on the labour and credit market

\footnotetext{
${ }^{5}$ An important case on the plurality of explicatory models is that of the so-called "institutional equivalence" (Schmid and Schonmann, 1995), about active labour policies in the 1990s, according to which comparable objectives and functions are pursued also through regulatory and allocating mechanisms and different incentive systems.
} 
(self-employment, career opportunities, exit and re-entrance conditions, regularization from informal employment, micro credit and asset building). Although a cognitive framework offers a map of how to fit in entitlements and eligibility criteria for an individual beneficiary in his/her various interactions, more than a single map may be drawn. Depending on whether the standard hypotheses of the neoclassic theory or the heterodox hypotheses of evolutionary economics are adopted, the policy map may vary. In particular, in the first case, the main assumptions are, first, means and ends separation (i.e. the preferences in the allocation of lifelong time), and second, independence of policy desirable objectives in favour of reconciliation vis-à-vis actual preferences of target subjects, be they individuals or groups. In the second case, the hypothesis of co-evolution of means and preferences is assumed, and the channels through which preferences form and change are investigated (Bowles 1998). What follows is that the outcomes of the same policy design result different not because of the different formal institutional design, but because of the interaction between the latter and the variety of behaviours and the interactions of agents deterministic and unique in the first case, open and multiple in the second. In this respect, the "nature" of our cognitive framework for reconciliation policy is not merely an alternative allocative mechanism of resources, essentially time, at individual level, under the standard assumptions of exogenous and stable preferences, à la Becker. Rather innovatively, the proposed framework has the ambition to improve subjective wellbeing both within and outside the family to more equally share, and agglomerate spill-over benefits. This "nature" may be alternatively interpreted through the New Institutional Economics (NIE) or the Evolutionary Economics perspective.

In the NIE perspective, starting from North (1990), the very notion of economic system as well as thus the policy-induced process of economic and social change varies considerably. The "institution" category is, or can be, ambivalent, since it is a rule of an incomplete contract in an asymmetric information context. Yet, this rule can also minimize transaction costs. The ambivalent role of institutions would have a bearing on different policy outcomes, depending on which factors prevail in reality: that is, incompleteness or rational calculus to minimize costs. In the former case, the policy making process cannot be defined once and for all, before the economic system actually perform; this is because rules (i.e. the institutions) cannot by definition fit the feasible set of policy actions, subsequently chosen by many and heterogeneous actors. In the latter case, the role played by organizations may minimize the asymmetric information effects and make policy actions rational, given the constraint of transaction costs. ${ }^{6}$

By contrast, the Evolutionary Economy approach, defining the economic system as "a rule system contained in what we call the meso" (Dopfer et al. 2004: 163), mainly consists of explaining economic change, starting from the "meso domain," which in turn activates processes of microeconomic changes and macroeconomic consequences. The process of economic evolution, similarly to the Schumpeterian creative destruction, thus unfolds as a process of rule changing which, influencing both the micro and macro level of behaviours, is divided into three phases: (i) the emergence of a new rule, (ii) its adoption and adaptation through social learning, and (iii) its maintenance at global level. (As the form of a leading idea to which society conforms its behaviour at the global level, or, at the local level, as the update of the novelty introduced into the system by the rule). The limited ability to learn coevolve with cultural features and explain an economy's process of change: in brief, a

\footnotetext{
${ }^{6}$ According to Dixit (1996), the distance between "institutional rules" and actual "political economy actions” in each case represents the room for real policy choices and their change. However, the main limit of a cognitive framework, if designed according to NIE, would consist, according to Eggertsson (1998), in a deterministic thinking drift, when it adopts the standard hypotheses of "rational choice", though a bounded rational choice, to explain the policy-making process. Therefore, according to Eggertson, a cognitive framework aims at explaining the policy as an endogenous process explaining economic and social change and influenced thereby.
} 
system's driving force lies in the novelty of a rule, but its outcome is multiple and nondeterministic. Similarly, Witt (2003) develops the evolutionary perspective of a policy, meaning a real process by which "the positive and normative knowledge that informs the action of the agents involved can change through experience and induced inventive learning" (Witt 2003: 78, our italics): learning and communication about facts, values and aims are the key factors of policy making in a non-deterministic view. The adaptive solutions designed by public actors or private agents in an employment relationship in reaction to a new rule can play out differently, and, therefore, produce different effects in the medium run. They can be either transitional solutions, when the relevance of the gender policies decreases in the political debate or after market failures (e.g. low likelihood to reenter the labour market after maternity, non-compatibility of the fertility-employment choice) have been removed or, alternatively, they become an economy's new institution. These rules enrich the provisioning system of that economy, which, for instance, sets up the targets negotiation process among public decision-makers; orients the agenda setting; promotes the expression of marginal and latent interests; influences the perception of the benefits related to a mainstream behaviour. In this case, an adoption/adaption process follows the process of emergence of new rules. This can be represented by the fact that gender rights, as in the case of reconciliation, are not contingent but universal values and encompass a growing number of subjects (Barker 2005).

- Third answer: Considering the controversial literature across and within gender economics, feminist economics and feminist theory, a cognitive framework is a theoretical and political undertaking ${ }^{7}$. Feminist Economics hosted ( 1999 n. 5 and 2003 n. 9) this methodological debate, exploring how the various positions can be mutually complementary and what policy implications were arising. Starting from Lawson's suggestion that an ontological approach is a valid heuristics of women conditions, Barker (2003), Harding (1999), Nelson (2003) and Peter (2003) expressed their disagreement, more or less radically, with the idea that this approach is " capable of facilitating the emancipatory and epistemological projects that many feminists support” (Lawson 2004: 120). Based on the definition of the social reality as a open, structural, dynamical, intrinsically related domain, the ontological framework is about set "possibility" of human interactions and not about specific actualizations (Lawson, 2004: 122). On the one hand the nature of this framework is about "commonalities" shared by human agents and these commonalities make feasible the transformation of reality. This is the point of feminist attack: Barker questions " the grounds of shared interest, needs and motives” (Lawson:107) and the legitimation of social emancipation on "a recognition of common human nature." We would say that such a critique opens two questions: the first is theoretical and regards the nature of a metasystem of needs, interests and aims, the second is political and regards the task of empowering content of the metasystem. Nelson points out the transcendental aspect of ontology that continues to emphasize formal reasoning and a dicotomic way of thinking about "mechanisms... outside the experience," and hence rationality outside sentiments and moral motivations. In short, the core of this methodological debate can be summarized on how women conditions as a category is "socially built" and understood. This implies that (women) difference is a matter of resources inequality, norms, and ideology (Agarwal 2002), a matter of freedom in the space of capability (Robeyns 2003), a matter of human development (Nelson 2004), a matter of economic development ( Mikkola 2005, and us).

\footnotetext{
${ }^{7}$ Agarwal (2004) classifies this literature in three classes: orthodox, heterodox and marginal heterodox models depending, essentially, on the microeconomic assumptions (rational choice, independence of agent, power) on the main topics and on policy approach (equalizing differentials vs. social justice); Barker (2005) evaluates if and how radically feminst economics is able to" transform” mainstream economics; see also Robeyns (2000) about feminist methodology and Carbone and Cahn (2005) about a female pattern of rationality.
} 
In short, on the basis of these three ways of thinking about a policy, our idea is that the heuristic power of our reconciliation policy-specific cognitive framework consists of highlighting gender friendly policy weaknesses, and suggesting a theoretical trajectory, holding together policy objectives, institutional rules, and selected facts in terms of a two-way chains (see section five). Next section selects from the most recent debate of development economics those explanatory models, which we consider relevant to understand under what circumstances pro work-life reconciliation policies can sustain development processes.

\section{Reconciliation Between Poverty Traps and Aspirations: A Selected Review of Literature}

The modern theory of growth (Banerjee, Duflo 2005; Venables, Burgess, 2004) and the "frontiers of development economics" (Meier, Stiglitz, 2002; Ray, 1998, 2000) suggest categories and heuristics, which seem useful to build our cognitive framework. They offer a sort of "mosaic" of multiple explanations, based on the assumption that initial conditions matter because agents (in backward areas) "do not always avail themselves of the best opportunities afforded to them" (Banerjee, Duflo, 2005:). We take into account this broad literature, by selecting essentially two strands, one is related to poverty traps and the other to the agents' aspirations (Appadurai 2002; Ray, 2002). The former examines macroeconomic aspects with microeconomic consequences, the latter focuses on the space of individual decisions with macroeconomic consequences. Ray's view (2000) seems to play the role of bridging the two.

In a nutshell, Ray believes that the "history" of a country or the "agents' expectations" can explain both the development path of an economy and the differentials observed across countries or within the same country. Underdevelopment is "not as a failure of some fundamental economic parameters ... or socio-economic values, but as an interacting "equilibrium" that hangs together, precipitated by expectational inertia or by historical conditions" (Ray, 2000: 8, italics added). It is an approach that suggests two conclusions relevant for our topic. First, that convergence is not an automatic result and, therefore, gender policies formally designed to equalizing differentials may be weak. Second, that there are no such "fundamental" differences between an economy's agents that can make them more or less willing to save, invest, innovate, cooperate, etc. Thus, there are no genetic gender differences, but situations (such as power distribution, perceived gendered roles across markets, households, and social networks), in which women choices inherently differ.

As a consequence, the long-term path is a "self-reinforcing equilibrium" which in reality can be either a "historical self-reinforcing outcome" or an "inertial self-reinforcing outcome." In the first case, the unequal initial conditions imply the persistence of the current outcome, and the economy is entrapped in a sub-optimal equilibrium because of a threshold effect. The long-term equilibrium is deterministic. In the second case, the long-term equilibrium depends on the complementarities existing between agents' expectations - which may be optimistic or pessimistic: "beliefs that a bad outcome will occur do come true in the sense that such beliefs precipitate bad outcome" ( Ray, 2000: 16) and therefore different degrees of optimism or pessimism drive an economy from one status of equilibrium to the other. Hence the long-term equilibrium is of the multiple equilibriums type. Nevertheless, a crucial and still open question for this theory is "where do optimistic and pessimistic expectations come from?” (Ray, 2000: 5).

Poverty traps are conceptualised as cases of coordination failures (Hoff 2000) and the numerous models allow to understand why initial conditions matter to explain disparities. These models single out channels and constraints through which individual decisions, economic transactions, and linkages occur. Bowles et al. (2006) suggest a taxonomy of three classes of models. The first class is based on the critical threshold (Azariadis, Drazen, 1990) which enables an economy to undertake its development path or not. A significant case study is the one related to the consequences that a low human capital stock (the driving force) has on agents' education choices 
(the mechanism of propagation), which in turn affect long-run equilibrium. If an economy or a sector is characterised by an excessive supply of unskilled labour, this depresses salaries and keeps investments in education low. The economy or sector remains entrapped, because the pool of educated population is modest, which entails low productivity. In turn, opportunities for businesses to shift from traditional to innovative sectors are limited, meaning that firms are not encouraged to innovate if the human capital is scarce. If these assumptions are correct, the level of skilled labour demand and supply remains low, because of the growing returns on investments in education. A second class of models deals with the role played by institutions and various types of government failure (Banerjee, Duflo 2005; Bowles 2006). These types of failure have the effect of distorting private investment decisions because of too high or too low levels of protection. They also produce an insufficient and undiversified supply of social infrastructure and public good like care services; they do not foster coordination and cooperation between firms, with the obvious consequence that they are not willing to introduce innovations, such as organizational innovation promoting pro-life reconciliation, whose benefits are not completely internalized (Ciccone, Matsuyama, 1996). The last class of models explains poverty traps on the basis of agents' membership and social belonging, in contexts where exchanges are assumed not to be regulated by market conditions alone, but by the whole set of social norms (ethical values, habitual behaviour, shared mental models). The idea is that agents adopt behaviours, which are widespread within an economy, and if these behaviours are "bad" they discourage "good” behaviours (Durlauf 2006; Sen 2006).

Aspirations is a new heuristics of (disparities of) development paths, recently introduced from the cross-fertilization between anthropology (Appadurai 2002) and economics (Ray 2002). It is assumed to be a particular forward-looking rather than backward-looking "instance of culture."8 For our case, aspiration and aspiration change allow us to open the black box of subjective motivations underlying both preferences formation and choices. Three are the main aspects to be considered: (i) the individual aspiration building is socially determined because depends on the cognitive window; (ii) the capacity to aspire is multidimensional, including material conditions, dignity, power: depending on the place that an individual occupies in the interactions, its aspirations may be complements or mutual substitutes; and (iii) the aspiration gap is the difference between the standard of life that is aspired and the standard of life that is already achieved.

Two are the implications to explain how aspirations affect individual decisions: the first is that only if the aspiration gap is positive, it would affect the future oriented decisions by requiring an individual effort to change. The second is that, because of a positive relationship between aspiration gap and effort, if the aspiration gap is high then individuals perceive that it is far beyond their means to fill it. Thus, individuals are less prone to invest and innovate. Again for our case, because the aspiration window is defined in cognitive terms, then a single policy is not enough to build and sustain the individual ability to aspire (e.g. training course, volunteering action to promote collective participation, income support) to contrast both setting agenda effects and threshold effect.

Yet, although these different strands of development economics literature highlight the key explanations of persisting disparities between regions, groups, and individuals, there still exists a gap in the understanding first, through what channels (i.e., culture, role models, values, labour market positions, and the family relations) policy benefits and opportunities are perceived and hence work-life choices are formed across different contexts. Second, which newly generated interactions are possibly conducive to higher economic development prospects. For this purpose, next section develops a critical taxonomy of the existing European Union (EU) gender mainstreaming policy approach.

\footnotetext{
${ }^{8}$ As well known, the literature on "culture and economics" and "culture and development" is very broad and multidisciplinary; see Jha (2004) for a survey on various models that, starting from the increasing disaffection with the metaphora of homo economicus (from '60 and '70), investigate factors affecting “identities” of individual ( e.g.status, tastes, role, social preferences,conformity).
} 
Throughout the EU, gender-oriented policies are cross-cutting initiatives incorporated within the major axes of EU Structural Fund programs, calling for increasing integration of policy tools in different policy areas and sectors ${ }^{9}$. These policy measures draw on the so-called gender mainstreaming approach ${ }^{10}$ promoted within the framework of the European Social Model. This implies active social inclusion through fostering female participation in labour market, while assuring social services and life-long education and learning. As the aim is to explicitly infuse a gender perspective across the broader policy spectrum, so work-life reconciliation initiatives ${ }^{11}$ bridge workfare programs with welfare provisions (Caroleo and Garofalo, 2006).

This section critically presents a taxonomy of EU gender friendly policies, which have been designed and implemented across Italian Objective 1 regions. The analysis examines these measures from the perspective of work-life reconciliation, which is currently the test for the European Social Inclusion model to prove the extent to which it is able to act effectively on gender equality by addressing the difficulties of work-life balance now affecting all families throughout Europe $^{12}$. This newly emerging policy objective becomes even more relevant across contexts, which are economically lagging behind, such as the Italian South. In such circumstances, promoting work-life reconciliation within families may work as a strategy to harness human and economic development across local communities.

In Italy, both at the national and regional level, three areas can be identified as gender friendly policies for work-life reconciliation (as shown later on in Tab. 2): (i) active labor market incentives, (ii) social inclusion, and (iii) entrepreneurship. Promoting female (self)employment while assuring broader social assistance programs is an explicit aim emerging out the 2004-2006 National Plans for Employment and Social Inclusion, the 2000-2006 Regional Operational Programs funded by the EU Structural Funds, and the recently-enacted Laws n. 53/2000 and n. 328/2000 (Ministry of Labour and Social Policy, 2002). These different pieces of legislation and public spending programming offer monetary incentives for making working time arrangements and conditions more flexible, strengthening social service at the local level. Over the past programming cycle 2000-2006 of EUs Structural Funds, in particular, Objective 1 regions (namely, Campania, Apulia, Basilicata Calabria, Sicily) have sought to make welfare provisions formally complementary with employment schemes, with the aim to reinforce local development processes. The main assumption is that work-life reconciliation can be achieved through an integrated policy approach to increase female participation across markets and social networks, leading, in turn, to gender equality and economic development over time ${ }^{13}$ (Robeyns, 2003).

\footnotetext{
${ }^{9}$ In this context, because the availability of resources from the European Social Fund (Measure E1) for assistance with entrepreneurship schemes is predicated on a matching with the European Employment Strategy (EES) concerns, gender-mainstreaming issues have received more attention (Rubbery, 2002).

${ }^{10}$ As reported by Rubery (2002): "Gender mainstreaming is the (re)organisation, improvement, development and evaluation of policy processes, so that a gender equality perspective is incorporated in all policies at all levels and at all stages, by the actors normally involved in policy-making”' (Council of Europe 1998: 13, in Rubery, 2002: 2).

${ }^{11}$ As Rubery (2002) notes, there are a number of factors that can explain why these policy areas have been particularly susceptible to influence from the EU and its gender-mainstreaming requirement. Active labor market policies were the initial cornerstone of the National Assistance Plans (NAPs) - a situation reinforced by member states being asked to meet specific targets for assistance to the unemployed. Accordingly, several EU member states have introduced targets or even quotas for women's participation, and several have opened up their policies to women returning from inactivity, not simply to those registered for benefit purposes as unemployed. Some countries also have provided extensive training to their employment service officials to improve gender awareness in placement and training efforts (Rubery, 2002).

${ }^{12}$ It is worth noting that across the EU, many countries have extended leave entitlements, though these are often on an unpaid basis. More positively, there have been many initiatives to at least extend periods of leave time reserved for fathers and to increase the flexibility of leave arrangements (Rubery 2002).

${ }^{13}$ Based on semi-structured interviews and document analysis of relevant official policy reports.
} 
For this purpose, a whole new institutional architecture has been built both at the central and regional/local level to mainstream the gender perspective. Tab. 1 indicates the new institutions, which have been created to perform coordination, monitoring and evaluation of gender-oriented policies, as well as to initiate new policies explicitly pursuing gender positive actions. ${ }^{14}$ The extent to which these new institutions effectively work, though, is questionable. Conventional wisdom is that there seems to be multi-level interconnections between the European, central and regional government agencies, but persisting disjuncture with local authorities in detecting social needs for strategic policy making. ${ }^{15}$ Yet, the assessment of the institutional setup associated with gender friendly policies is beyond the scope of this section, specifically devoted to the analysis of the premises underlying gender policies for work-life reconciliation.

Tab. 1 - Institutional innovations to promote gender mainstreaming found in Italian central and regional governments, 2000-2006

. Ministry for Equal Opportunities with authority in gender mainstreaming

. Inter-ministerial committees, steering committees or work groups, or committees at the office of the presidency

. Departments, units, and task forces with specific competences or evaluation and monitoring duties both at the national, regional, provincial, and municipal levels

. Parity or equality advisors on key committees or ministries at the national, regional, provincial, and municipal level; mechanisms for gender analysis of the budget

. New equal opportunities acts requiring mainstreaming; drawing up of national strategies or regional plans for equality

. Mainstreaming or gender assessment in individual ministries, and all public agencies and public services

. Methodologies or guidelines for gender mainstreaming of government policies or employment policies

. Gender assessment of all new pieces of legislation

Source : Our elaboration on Rubery, Grimshaw, and Figueiredo (2001).

Building upon Sen's (1999) categories of entitlements and capabilities, Tab. 2 encapsulates those gender friendly initiatives, which have been designed and implemented by Italian Objective 1 regions over 2000-2006. According to our cognitive framework (section one), we suggest classifying them as entitlements for specifically targeted groups of women such as (wouldbe)entrepreneurs, working mothers, female unemployed, poor and lone parents with dependents as well as other heterogeneous female beneficiaries at risk of social exclusion. Accordingly, benefits and training for workers as well as incentives for entrepreneurs emerge as the most frequent solutions designed for those, who are out of, or hold a weak position in, the regular labour market, ${ }^{16}$

\footnotetext{
${ }^{14}$ From an institutional perspective, gender mainstreaming builds upon multilevel governance structures and relations. At the supranational level, the European Commission, specifically within cohesion policies, has set out a clear commitment towards equal opportunities and delegated at the national and regional governments the actual implementation of this principle. At the national level, in Italy, there has been created the Ministry for equal opportunities, which acts directly to promote specific initiatives and oversights other ministries' programs to guarantee the gender perspective. Its formally assigned tasks, therefore, revolve around two fundamental functions, that is, programming affirmative actions in support for the conciliation of and coordinating other institutional agents for them to embody an equal opportunities' agenda and code of conduct. Of such functions, what seems predominant is the "oversight/coordination” effort that implies a continuous formal and informal interaction with the other institutional agents to influence their system of beliefs and actions.

${ }^{15}$ This conclusion has been also confirmed by semi-structured interviews with regional policy makers.

16 These women may work irregularly either because of structural economic constraints or by choice (see Marra, 2004; Meldolesi, 2005). It is estimated that Campania Region's GDP is underestimated by 30 percent, which represent the share of irregular activities escaping the official statistical analysis. At the national level, according to the National Institute for Statistics (ISTAT), the informal sector amounts to 18-20 percent of the officially estimated GDP. Overall, in the South of Italy, in 2002 irregular workers are 23 percent of the total amount estimated nationally, more than double of the estimated amount for the North. Calabria shows almost 30 percent, of total employed workers (tree irregular workers in ten), followed by Campania (25.1 percent), Sicily (25 percent), Basilicata (21.5 percent), Apulia (21.1 percent), and Sardinia (17.7 percent) (see Istat, 2005; Meldolesi, 2004).
} 
and hence are exposed to poverty. Social services are, therefore, meant to support these beneficiaries, who may also present psychological and other dysfunctional family-related problems.

Tab. 2 - EU Regional Gender Friendly Policies Through the Lenses of Entitlements and Capabilities

\begin{tabular}{|c|c|c|c|}
\hline Policy Areas & Policy Measures & Entitlements & Capabilities \\
\hline \multirow{3}{*}{$\begin{array}{l}\text { Active labour market } \\
\text { policies }\end{array}$} & $\begin{array}{l}\text { Work-life } \\
\text { reconciliation }\end{array}$ & $\begin{array}{l}\text { Arrangements for flexible } \\
\text { paid work time negotiated at } \\
\text { the individual level (Art. } 9 \\
\text { Law 53/2000). } \\
\text { Women already at work in } \\
\text { manufacturing and services } \\
\text { as well as public agencies }\end{array}$ & $\begin{array}{l}\text { Work-life reconciliation } \\
\text { practices } \\
\text { Sharing responsibilities for } \\
\text { caring labor and work duties } \\
\text { Self-realization }\end{array}$ \\
\hline & Job creation & $\begin{array}{l}\text { Equal opportunities for } \\
\text { gender (no specific targeting) } \\
\text { Subsidies or quotas for } \\
\text { female recruiting (Measure } \\
\text { E1, European Cohesion } \\
\text { Policy ,specifically across } \\
\text { Ob. } 1 \text { regions) }\end{array}$ & $\begin{array}{l}\text { Labor and managerial skill } \\
\text { development } \\
\text { Employability }\end{array}$ \\
\hline & Vocational training & $\begin{array}{l}\text { Training offerings } \\
\text { (manufacturing } \\
\text { Services) both on the job or } \\
\text { in formal classrooms for skill } \\
\text { conversion }\end{array}$ & $\begin{array}{l}\text { Higher/better education } \\
\text { Labor and managerial skills } \\
\text { development } \\
\text { Employability }\end{array}$ \\
\hline Entrepreneurship & Business start-ups & $\begin{array}{l}\text { Subsidies for female business } \\
\text { start-ups (no specific industry } \\
\text { targeting) }\end{array}$ & $\begin{array}{l}\text { Entrepreneurship } \\
\text { Managerial skills } \\
\text { Leadership }\end{array}$ \\
\hline Social inclusion & $\begin{array}{l}\text { Benefits and welfare } \\
\text { services }\end{array}$ & $\begin{array}{l}\text { Income-based social } \\
\text { assistance for households } \\
\text { (childcare, elderly care and } \\
\text { support, disabled assistance) } \\
\text { Individual and household- } \\
\text { based welfare allowances } \\
\text { (unemployment benefits, } \\
\text { household support, pension) }\end{array}$ & $\begin{array}{l}\text { Individual and household } \\
\text { welfare } \\
\text { Empowerment } \\
\text { Social inclusion }\end{array}$ \\
\hline
\end{tabular}

From the analysis of these policy measures, it appears that policy makers' concern for worklife reconciliation has been thus far associated with various forms of social exclusion such as educational disadvantages, long-term unemployment, low paid (irregular) working positions, marital instability. In such circumstances, the gender gap is interpreted as a state of need, emerging out a condition of economic, social and cultural vulnerability, ${ }^{17}$ which may exacerbate over time. Thus, in keeping with the origins of every public policy, ${ }^{18}$ the consequences of such vulnerability are no longer conceived as private individual risks but are taken out of the private sphere and

\footnotetext{
${ }^{17}$ Relevant is the concept of "vulnerability” to poverty, developed by Orloff (1996) as emphasized by Addis (2002). The idea is that people may enjoy a given level of material well being using resources provided by the welfare state. These provisions may be effective in transferring resources to the family, yet they may still be quite ineffective in making women in the family non vulnerable to poverty, if the entitlement of the benefit belongs to the male breadwinner (Addis, 2002).

${ }^{18}$ This perspective is typical of the welfare economics approach to public policy.
} 
granted protection from society. ${ }^{19}$ Key policy indicators are the individual and household income level, years and type of education, skill features and shortage, the health status, and the rapidly changing composition of the family, coupled with the marked demographic transformation and the work evolving conditions. This set of indicators quantitatively and qualitatively profiles a situation of growing socioeconomic risk (Istat, 2005; Fondazione Brodolini, 2007) ${ }^{20}$.

Fig. 1 - Factors affecting work-life reconciliation within the economy

Social reproduction

Low

High

Low

\begin{tabular}{|l|l|}
\hline $\begin{array}{l}\text { Gender inequality } \\
\text { Poverty traps } \\
\text { Underdevelopment }\end{array}$ & $\begin{array}{l}\text { Social justice } \\
\text { Human development } \\
\text { Productive ineffiency }\end{array}$ \\
\hline $\begin{array}{l}\text { Gender inequality } \\
\text { Productive efficiency } \\
\text { Low human development }\end{array}$ & $\begin{array}{l}\text { Gender equality } \\
\text { Productive efficiency } \\
\text { High human } \\
\text { development }\end{array}$ \\
\hline
\end{tabular}

The work-life reconciliation policy approach consists then of providing financial resources, technical assistance, and services in kind to both individuals and households. The aim is to fill the specifically diagnosed socioeconomic or psychological gap, which would hinder the attainment of the socially desirable balance between production and social reproduction. ${ }^{21}$ The underlying policy assumption, as schematically shown in Fig. 1, is that a trade-off exists between productive efficiency and social justice, which shapes both the micro and macro optimal equilibrium between work and caring labor in Western advanced economies ${ }^{22}$.

\footnotetext{
${ }^{19}$ Data reported by the OECD (1999), for example, show that from the mid-1970s to the mid-1990s, there was quite a clear increase in the population share of single person families, single adult families with children, and of households made up of two or more adults without children. In contrast, there has been a remarkable decrease in the proportion of households with two or more adults plus children. The same data also highlight the changes in the distribution of household types distinguished according to their economic characteristics. If we consider households in which the head of the family is of working age, it emerges that there has been a clear decrease in the population share of households with only one worker, whereas a slight increase is seen for households with two or more working members. It is also interesting to note that the same statistics show no decrease in the share of households without any working members. On the contrary, the population share of this group seems to be on the increase (Fondazione Brodolini, 2007).

${ }^{20}$ Based on semi-structured interviews.

${ }^{21}$ As Ciscel and Heath (2001) note, social reproduction, defined as the daily and intergenerational renewal of human resources, is integral to the economy though overlooked in conventional economic theory. However, the concept of social reproduction as elaborated in feminist political economy is not synonymous with domestic labor. Domestic labor involves the daily tasks associated with the maintenance of the labor force, while social reproduction also encompasses intergenerational renewal, through the activities of sexuality, biological reproduction, and raising children.

${ }^{22}$ By contrast, Elson and Pearson (1981) apply gender analysis to simple growth models, identifying economies as gendered structures. In contrast to the "dis-aggregation approach,” which disaggregates the economy into a male and a female economy, she proposes the incorporation of gender as a power relation. This enables her to envision a growth path in which linkages between production and social reproduction are supportive of gender equality, productive efficiency, and human development.
} 
From a theoretical stand point, the conceptual framework underpinning the current work-life reconciliation approach draws on standard economic theories of public choice and the welfare economics, centered on equilibrium, and assuming self-interested individuals and perfect or almost perfect information. ${ }^{23}$ Accordingly, current gender friendly policies are justified on the need to redress specific conditions of work-life imbalances (as highlighted in Fig. 2) arising over the lifespan of individuals and/or a households. ${ }^{24}$ Yet, such policies intervene only when and where such imbalances give rise to increasing socioeconomic risks.

Fig. 2 - Unbalanced patterns of work-life reconciliation over time

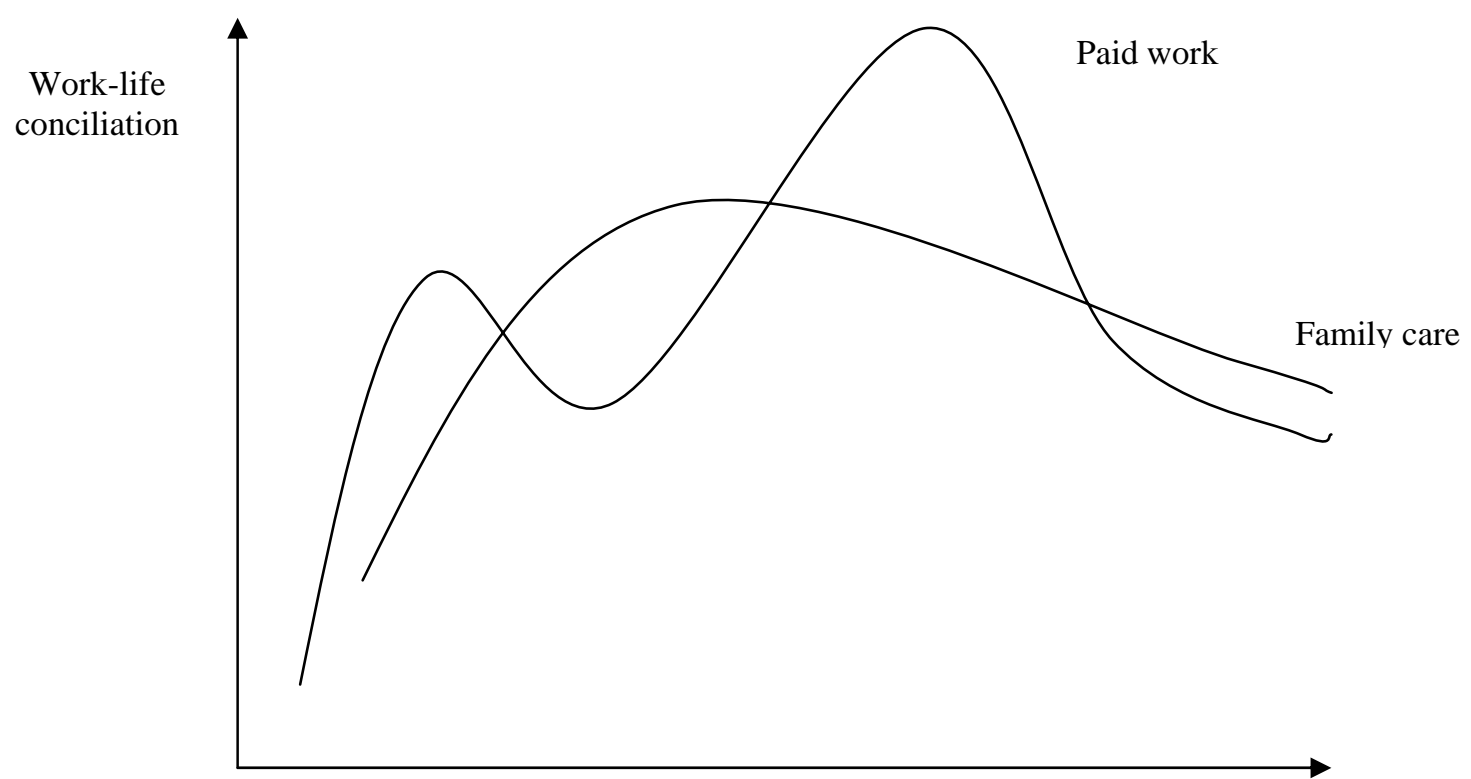

Time

Paraphrasing Ferrera (1997), this approach is predominantly built on the notion of vertical solidarity, whereby work-life reconciliation becomes a relevant policy goal as long as it relates to allocative efficiency considerations, such as exiting poverty, building human capital, broadening economic opportunities both at the individual and household level. ${ }^{25}$ As a result, the expected outcomes are increased women's employability, entrepreneurship, leadership, and empowerment as well as raised female awareness on such issues as health, motherhood, child welfare, disability, violence, human rights, and self-realization. These are individually- and family-based capabilities (shown in the last column of Tab. 2) enabling work-life balance at the micro level. These modified conditions of choice can, in turn, nurture human development, overcoming existing socioeconomic cross-gender inequalities, and hence assure higher economic growth prospects at the macro level (Robeyns, 2007).

\footnotetext{
${ }^{23}$ See Witt (2003) on this point.

${ }^{24}$ Public choice theory builds upon methodological individualism, whereby though households may be considered relevant units of analysis, these are assumed to hold preferences and behave like individuals.

${ }^{25}$ At the international level, Jackson (2001) picks up the theme of institutionalization in the context of poverty. She discusses the instrumentalist approach of most development agencies that regard gender as an instrument for other development goals. By providing a thorough critique of poverty concepts and measurements, she argues that antipoverty policies cannot substitute for gender analysis, because the feminization of poverty is not only about women becoming the majority of the poor, but also about poverty being a gendered experience.
} 
It is clear that this policy approach (and rhetoric) shows a number of methodological interactions and points of overlap with Sen's capabilities perspective. Yet, this perspective is truly embraced only to the extent to which promoting human development drives the policy focus on changing individual and family choice conditions to improve social functionings. Yet, this approach may end up resulting supply-side if it merely transfers a set of financial benefits, knowledge and professional skills to increase female paid work, assure family care, reduce poverty and social exclusion through unidirectional, hierarchical, and coercive governance structures and relations (formal vertical subsidiarity). In these circumstances, gender seemingly integrated initiatives reduce to mechanical, and juxtaposed measures, flowing from government agencies to beneficiaries, and unfolding within an institutional/organizational vacuum. Public agencies or their delegated profit or non-profit organizations provide training or disburse cash or other financial allowances to female beneficiaries to address a priori explicitly codified needs. Feedback from beneficiaries, in case it is institutionally built into the policy cycle, is meant to overcome potential policy failures (Witt, 2003), but it is not the base to detect latent, unexpressed social demands as well as tacit uneasiness related to sharing responsibilities for breadwinning and caring labour.

In other terms, this policy approach overlooks cross-gender differences in the way work-life balance is pursued within different institutional contexts and ignores within-gender heterogeneity (Litton Fox, Murry, 2003). So, for example, to increase female participation in labour market, all unemployed women may become potential targets regardless of their specific working situation, their values, preferences, and aspirations for getting a job and pursuing a career. Nor is work-life reconciliation acknowledged as a process with potentially multiple equilibria, which vary according to the characteristics of the environments where couple beneficiaries live. The conclusion is, therefore, that the meanings, and reactions by different recipients to the incentives and opportunities provided by the policies are expected to remain invariant across gender and contexts. As a consequence, this approach can be of limited help to understand the effects of work-life reconciliation on different groups of people, like mothers, single person households, or two-parent families (Mikkola, 2005). The questions of how and why gender friendly policy initiatives can actually create the desired individual and family-based capabilities promoting work-life reconciliation practices for economic development are still open to debate. Next section turns to addressing this issue.

\section{Gendered Roles and Power: The Potential Policy Impact on Work-Life Reconciliation}

Considering gender as women's behaviour differing from that of men as well as among women themselves in different contexts implies that a single explanatory model is clearly not applicable. Furthermore, if the empirical base comes to rest on analyses of large-scale, nationalsample, survey data sets, which presume gender neutrality in their measures, then to that extent we are unable to gain insights on work-life balancing strategies and the ways in which policies can strengthen them. Following up on the critical taxonomy presented above, this section adopts our evolutionary approach to identify those microeconomic factors affecting work-life reconciliation choices, while the macro consequences are dealt with in the subsequent section five. From two different angles, we analyze first, how similar policy opportunities, provided to similar agents, generate different reactions because of inherently subjective characteristics; and second, we take into account to what extent and how policy opportunities vary depending on contextual characteristics (i.e., geographical, institutional, productive).

For this purpose, we zoom our interpretative lenses on the microeconomic mechanisms, which do not reduce to the individual decision making, ${ }^{26}$ but they are activated within ethical interactions - the functionings in Sen's words (1999). Going even beyond Sen’s approach, this

\footnotetext{
${ }^{26}$ Not as methodological individualism but ethical individualism to substantiate individual freedom as the ultimate aim of the policy (Hill, 2007; Robeyns, 2007, 2003). For a broader debate on the different meanings of methodological individualism, from a restrictive view to a inclusive one encompassing the ethical dimension, see Hodgson (2002).
} 
ethical individualism (Hill, 2007) may act as a driving force to generate change in observed social interactions, for example, within the household, on labour market, for purchasing care services, and public goods provision. In line with the realist approach to policy analysis and evaluation (Pawson, Tilly, 1997; Pawson, 2001), we then detect cognitive, affective/motivation, and economic mechanisms, which public policies may or may not trigger across different contexts and different recipients within the same context depending on the real case. In fact, building upon the evolutionary perspective (section one), the first step of our cognitive framework consists of coding how the novelty introduced at the meso level, that is, the different policy measures for reconciliation, activate consequences at the micro level regardless of the specific context where there are expected to be adopted/adapted.

In this perspective, the policy measures thus far described facilitate work-life reconciliation as long as they enable (i) cognitive, (ii) affective/motivational, and (iii) economic mechanisms of behavioural change within heterogeneous recipients across different family and market transactions. By leveraging financial resources, affective reactions (Nelson, 2004), and cognitive insights, ${ }^{27}$ gender friendly policies may give rise to more balanced work-life reconciliation choices at the individual, family, and social level. This choice process to balance work and private life, though, may lead to controversial solutions depending on the specific situation at hand. For instance, increasing the minimum wage, mandating shorter work weeks, instituting wage protections in deregulated industries, mandating proportional benefits for part-time and contingent employment, and implementing re-employment insurance are all, and oftentimes alternative, gender friendly initiatives that would modify the cost-benefit calculus of the household. ${ }^{28}$ This would entail expectations for higher income and social status, coupled with the shared responsibility for caring labour within the family. Furthermore, fulfilling women's aspiration for playing a professional as well as a political role within the community may sustain mothers' return to work from inactivity as well as communities' strategies for mutual caring help ${ }^{29}$. Life-long learning through formal higher education and on-the-job training may lead more educated women to look for better work opportunities out of the black market or to negotiate more extended parental benefits and leaves, as suggested by the development literature on aspirations (illustrated in section 3). Last but not least, raising awareness on human rights violation, violence, and discrimination may empower those disenfranchised trafficked women (frequently migrants) to denounce exploitation and improve individual and family well-being.

All these examples illustrate just one side of the work-life reconciliation process at the micro level. Thus, those measures listed in column 3 of Tab. 2 - such as job creation, work flexibility, vocational training and life-long education, business-start-up incentives, and social assistance have considerable potential to shift the unbalanced work-life reconciliation patterns from the traditional patriarchal organization of the family towards different degrees and modalities of shared responsibilities for breadwinning and caring labor (Folbre, Nelson, 2002).

The other side of the story is that, though policies offer similar opportunities to similar agents, similar agents behave differently and react to policies in unpredictable ways because of context disparities. In fact, the crucial point is what happens when these policies are adopted/adapted within different territories in the Italian South. In such contests, different living conditions between urban centers and rural areas highlights profound differences in the reconciliation paths potentially activated by the above examined policies. Urban centers are more exposed to work-life imbalances than rural ones where life may still unfold along traditional

\footnotetext{
${ }^{27}$ It is particularly interesting Hill's notion of liberating knowledge as a way achieve power to develop a capability (2007).

${ }^{28}$ For household, we do not build on Becker's standard assumption considering the family as a whole individual unit, but we take into account the different positions of different agents within the family. As Sen et al. (2003) point out, many are the available solutions of cooperation game within family.

${ }^{29}$ The project called Mothering Nests implemented in different neighbourhoods in Naples, for instance, employs poor women at minimum wage as tutors or baby sitters in childcare centers, receiving kids from those working mothers living in the neighbourhood.
} 
rhythms. Yet, rural contexts (specifically the interior zones of Campania, Basilicata, Sicily and Apulia) may present a more polarized situation: either women devote very little time to paid work and therefore lesser is the conflict for managing work-life needs within the family, or deeper conflict can be accentuated because of the distance and time for commuting from the center where all productive activities are concentrated.

In addition to this geographical factor influencing the ways different individual and families pursue their reconciliation strategies, as schematically shown in Fig. 3, we can isolate at least two other factors affecting the evolving work-life reconciliation patterns over time at the micro level. These are (i) the gendered perceived role, and (ii) the power processes overtly and covertly unfolding within the family (Litton Fox, Murry, 2003). The gendered role perspective sheds light on the difference between the sex of the person playing a role and the gendered nature of the role, which in turn shapes personal views, structures social action and cultural values (Litton Fox, Murry, 2003; Herts, 1997). This factor reflects how women's aspirations are formed and whether, how, at what costs they can be modified essentially according to the situation, in which they act - à la Nelson (2003). So, for instance, caring labour has been, historically, the unremunerated work for women: with the increasing supply of services, the discrete activities of women's work in households are increasingly available for purchase-usually produced by women's labor-by families with sufficient incomes.

Yet, work-life reconciliation is not an automatic result of the growing availability of purchased caring labour ${ }^{30}$ since, even in dual earner family there may still persist a situation of asymmetric gender relations, which is exacerbated when both earners are marginal working poor (Addis, 2003). In other words, if child and elderly care is perceived as an exclusive female role, there will be a latent or open conflict within the family to the extent to which the mother is engaged in paid work and is forced to or chooses to delegate caring labor to the market (see Fig. 3). The gendered role perspective highlights the flawed assumption that female and male roles are interchangeable and that policy can employ measures without regard to the potential for differential meanings to men and women. ${ }^{31}$

With respect to economically lagging regions of the South of Italy, two-income families find themselves with increasingly diminished economic resources and diminished control over their lives to systematically purchase caring labour. As a consequence, welfare provisions hold a considerable potential to support reconciliation schemes, specifically when they are tailored to lowincome families, or marginalized working poor. Yet, social assistance is not sufficient to assure work-life reconciliation to the extent to which variability of social service supply is significantly high across contexts, undermining service quality and efficacy. Furthermore, as middle-class families experience increasing precarious working conditions, access and eligibility for welfare services are shrinking. ${ }^{32}$

Fig. 3 - Factors affecting work-life reconciliation patterns within the family

\footnotetext{
${ }^{30}$ A recent ISTAT report on work-life reconciliation shows that both in the North and in the South of Italy day-care centers are not the first family choice for childcare. Families seem to prefer granparents' help or other family support because of a number of reasons: (i) grandparents' role for passing values and experiences on to children; (ii) the lack of time flexibility of the existing public facilities, which frequently close too early during the day or during summertime; (iii) the high monthly tuition as well as the high selectivity for admission of public day-care centers; (iv) the far distance of the facility from home and/or the difficulty due to traffic jam in reaching the job place; (iv) quality issues related to personnel, structure, and service. See ISTAT (2005a, 2005b). Actually, the main critique to this approach is that it preserves and superimposes the traditional arrangement of care provisions using as an input women's time and men's money (Addis, 2002).

${ }^{31}$ For instance, in the measurement of parenting, widely used in studies on domestic violence, assumes that such terms as conflict, argue, and hit are interpreted in similar ways by men and women (Litton Fox, Murry, 2003).

${ }^{32}$ Middle-class families with dependents hardly find in social service supply satisfaction to their reconciliation needs. They may be situated in the second quadrant of the table in Fig. 3, where a major gap arises between the usually standardized welfare supply as opposed to the variability of social demands.
} 
Gendered perceived role

Family care

Paid work

Male

breadwinner

\begin{tabular}{|l|l|}
\hline $\begin{array}{l}\text { Openly accepted gendered } \\
\text { division of labor and } \\
\text { dependent care }\end{array}$ & $\begin{array}{l}\text { Tacitly accepted gendered } \\
\text { division of labor Female } \\
\text { unremunerated care Latent } \\
\text { conflict within the couple for } \\
\text { the division of work and } \\
\text { family care }\end{array}$ \\
\hline $\begin{array}{l}\text { Reconciliation schemes to be } \\
\text { continuously renegotiated } \\
\text { Shifting cooperation and } \\
\text { fairness over time }\end{array}$ & $\begin{array}{l}\text { Marketization of caring labour } \\
\text { Open conflict in work-life } \\
\text { reconciliation } \\
\text { Assumed interchangeable roles } \\
\text { between men and women } \\
\text { Social ties at risk }\end{array}$ \\
\hline
\end{tabular}

Additional motivations explain why social assistance or market mechanisms cannot be considered as the panacea for work life reconciliation needs. This has to do with the fact that the values of personal, economic, and social freedom to recur to care services for dependent care meet limited recognition in the South, as being perceived, as an informal rule, putting at risk one of the most important non-market institutions that promotes community (see Fig. 3). In backward contexts, it is not culturally accepted that mothers leave their kids for the whole working day, and extended family is still highly valued specifically by working women themselves, who frequently feel guilty for the time spent outside the household. This affective/emotional reaction raises a barrier to purchased caring labour, which adds to the inherent limit to delegating the mothering function to market mechanisms. Paradoxically, there is an unexpected overlapping as regard to reaction to care services both from backward and advanced environments. In the first, women's role is still relegated to family care and thus the maintenance of traditional values reduces the female capabilities set, market size and diversification. In the second, the radical rejection of the pervasiveness of marketization justifies the return to family care as a crucial dimension of human life. This implies that reconciliation is a complex choice, which is not done once and for all, but it is continuously reconsidered over time according to the constantly changing family needs and working constrains and opportunities. In this perspective, work-life imbalance may persist and fairness and family cooperation may vary in degrees according to the extent to which traditionally gendered roles are ingrained and perpetuated.

We come back to our basic conundrum: can gender friendly policies ensure women's participation in the labour market while rejecting the notion that all familial activities must be commodified in order to do so? The traditional response is predicated on the assumption that caring labor and the market are mutually exclusive modes of social organization. This assumption can lead 
to the discriminatory conclusion and practice that individuals (women) should have limited access to the market in order to perform these non-market activities. This is exactly the way the glass ceiling works for women, who find a number of formidable obstacles if they intend to juggle family and career. They are then forced tacitly or openly to make a choice as isolated individuals, though the consequences (externalities) of such a choice extend to the family and community where they live. Thus, it clearly emerges that when and where the predominant belief system is aligned with the traditional patriarchal values, gender friendly policies may be weak mechanisms for changing the tacitly shared gendered role perspective. An illustration of this conclusion emerges from the official mid-term policy evaluation of the structural fund measures for female self-employment and business star-ups implemented in Apulia. The remarkable presence of female partners across corporate boards of newly created agricultural firms was explained just as the opportunistic capture of regional subsidies, rather than the inherent change in the familial or productive organization existing across rural areas of Apulia (Mid-term evaluation of Operational Regional Program of Apulia, 2006). Power structures and relations have remained, therefore, unaltered despite the seeming success of the policy!

This observation shifts the attention on the importance of power processes (see Fig. 3), both visible and latent, which are crucial to appreciate gender inequalities and conflicts emerging within the couple, hindering reconciliation patterns. The power dimension sheds light on the subtle ways male domination and female submission perpetuate in modern couple relationships within Western advanced societies. Family research (Hertz, 1997; Marks, 1998) emphasizes, for instance, that despite the couples' self-description as egalitarian, gender inequality is perpetuated by subtle power processes that are both visible and latent. ${ }^{33}$ In this regard, economic change mechanisms may have a strong bearing on the power relations within the family. Conventional wisdom is that through economic independence women can achieve greater power on their own lives and therefore more influential decision making power on the key family issues. Yet it is oftentimes overlooked how female income is considered and perceived vis-à-vis male income. Mansdotter et al. (2007) note that the base case of production losses due to parental leave, and of savings due to decreased sickness leave, is calculated by sex-diverse income, building upon the assumption that men produce more of societal value than women. The authors develop a number of alternative reasons to justify the variant of mean income by gender equality reasoning ("women's lower income should not be used to distort the division of parental leave"), health equity reasoning ("men's higher income should not be used to attach relatively more value to added male health") and rational reasoning ("the sex difference in income does not characterise the true difference in women's and men's productive value”).

Thus, the way women's income is understood highlights how it is interpreted the fact that women can contribute to breadwinning and whether this is considered just a mere addition to the household or substantial to maintain a certain social status. In this regard, recent jobs, which have been created or supported through more flexible contracts (from so-called "Pacchetto Treu" of 1996 to Law n. 30/2000) with a fast track for women may have assimilated female and male paid positions as well as earning capacity. In case of parental leave for childcare, the choice to forego one source of income - usually that of the woman - may no longer be taken for granted. Thus, the potential for the recently introduced active labor market policies to alter the existing unbalanced power relations within the couple is related to the extent to which such measures succeed in

\footnotetext{
${ }^{33}$ Viewing one's marriage as equal and family roles as egalitarian, despite experiencing marital inequality, serves several functions in preserving marriages. It conceals the existence of male domination and female submission in modern couple relationships and keeps partners from recognizing the existence of covert power, which if acknowledged could create marital conflict. Hertz (1997) reports that wives were more likely than husbands to accommodate their partners' needs or desires and to speak of fitting their lives around their partners' schedule. In addition, wives were more likely than husbands to describe attending to their partners' needs, worrying about upsetting or offending their partners, and doing what their partner wanted or needed. Other researchers have reported similar gender inequalities in marriages in terms of the subtle power processes involved in determining the direction of conversations and problems that get discussed in marriages.
} 
triggering a different cost-benefit calculus between male vs. female paid working positions, while strengthening the social acceptance for parental leave and shared childcare responsibility and active involvement. The economic change mechanism is not responsible on its own (and isolation) for more balanced work-life equilibria but only if it works in combination with other cognitive and motivational mechanisms. ${ }^{34}$ For highly educated couples, for instance, reconciliation tensions may arise as hidden within latent conflicts underlying the family life, which though may surface and lead to continuous negotiations for fair cooperation, à la Sen. These power shifting processes endogenously evolve towards pro reconciliation strategies as cultural values align with gender equality, and freedom as well as market or social services can free up time for the couple to rearrange their priorities. According to our evolutionary approach, individual preferences and policy outcomes co-evolve, activating a virtuous circle (Bowles, 1998).

The thus far developed observations on gendered roles and power relations lead to at least two conclusions. First, work-life reconciliation changes are caused by multiple factors and not linearly affected by one specific change mechanism, as anticipated in section two. This calls for embracing the complexity of socioeconomic phenomena as well as their interaction with policy measures and market mechanisms. Secondly and strongly related to the previous point, policy measures need to overcome the linear, standardized approach overlooking factors of subjective identities and contextual characteristics. Next section highlights the two-way chains connecting individual identities and contextual endowments.

\section{A Two-Ways Chain of Work-Life Reconciliation: Some Concluding Remarks}

This paper has highlighted that reconciliation is not just understood as a privately familial and individual dimension, which a single policy can effectively address, such as for instance, the working time flexibility measures. By contrast, reconciliation dynamically unfolds along multidimensional situations, depending on the different life-long interactions agents play. These interactions feed a process of cumulative causation, à la Hirschman - virtuous or vicious according to the specific case to be ethnographically explored. The preliminary evidence base, gathered thus far through interviewing and focus groups, which has underpinned the analysis presented in sections three and four, calls for further investigating social reality. The adopted ethnographic approach allows us to identify within a specific context, those driving forces and mechanisms of propagation promoting or hindering the adoption and adaptation of the novelty introduced by the policy and other institutional rules at the micro level. As illustrated in Tab. 3, the main driving force is human development (Ranis et al., 2005), including (i) a welfare dimension (i.e., caring, income benefits, human rights), (ii) an economic dimension (i.e., education, entrepreneurship, economic independence, market access and bargaining power), and (iii) a cultural/political dimension (i.e., conflict, cooperation, fairness within families, responsibilities and role sharing, personal selfrealization, aspirations gap, intrinsic motivations). These are driving forces in that they activate market and non-market linkages, and agglomeration effects (Hirshman 1958; Ray 2000; Burgess, Venables, 2004). Overall market linkages (i.e., externalities) entail the broadening and diversification of markets, such as increased transactions, heightened participation (in particular, in the labour market), asset building, newly emerging needs and wants. Non market linkages change interactions within the family, altering fair cooperation solutions (Sen, 2003), cultural values, and

\footnotetext{
${ }^{34}$ Mansdotter et al. (2007) argue that paternity leave indicates a departure from traditional masculinity. Hence, it could be associated with developing lifestyles more similar to the traditional female role like decreased alcohol consumption, improved food habits, and increased risk-aversion, which would affect mortality positively. Another potential reason for the decreased risks among men on paternity leave is healthy expansion of life roles. In the possible link between paternity leave and health are also included such conditions like divorce, number of children, later paternity leave, income development, etc. For instance, research has demonstrated that couples in which the father takes paternity leave are more stable than other couples, and that lone fathers have increased mortality risks compared to cohabiting fathers.
} 
perceived gendered roles. Both market and non-market linkages may positively cumulate up to a threshold leading to agglomerative effects.

Fig. 4 - Work-life reconciliation and development

Social cohesion and

economic development

Low-efficiency

equilibrium

High-efficiency

equilibrium

Investment

above the

threshold

Human

development

\begin{tabular}{|l|l|l|}
\multirow{2}{*}{\begin{tabular}{l|l|} 
Investment \\
below the \\
threshold
\end{tabular}} & $\begin{array}{l}\text { Social learning } \\
\text { Poverty traps } \\
\text { Low paid work } \\
\text { Gendered division of the } \\
\text { economy }\end{array}$ & $\begin{array}{l}\text { Policy learning } \\
\text { risks }\end{array}$ \\
& $\begin{array}{l}\text { Heightened gender } \\
\text { inequality } \\
\text { Social capital destruction }\end{array}$ \\
\hline
\end{tabular}

As schematically shown in Fig. 4, these agglomerative effects may, in turn, facilitate transition towards higher efficiency equilibrium development paths (Adserà, Ray 1998; Aoki 2007). So, for instance, closing women aspiration gap can be interpreted as an indicator of economic development in two specific circumstances. The first interpretation is that, as a matter of human development, the aspiration gap is filled because it is, indeed, very low. In this case, mothers go back to work from inactivity or low skilled women are employed in care service. These results, though, may activate just a indirect income effect. The second interpretation emphasizes that human development can retro-act on intrinsic motivations. In such circumstances, those women with a too high aspiration gap - who may be entrapped at a low level equilibrium, giving up their aspirations or even not nurturing any aspiration at all - modify the extremes of this gap (Appadurai 2002, Ray 2002). For instance, social cooperation can open up opportunities for poor women to get involved into mutual community care to overcome their psychological vulnerability. On-the-job subsidized training can employ women part-time, favouring skill-building, social interaction, and family care. Formalizing irregular working positions may allow for increasing productivity as well as fertility. Saving schemes can mobilize resources for inter-generational welfare. In short, a hirshmanian tunnel effect builds up a critical threshold investment for social mobility, essentially contrasting the predominant policy agenda setting (Witt 2003).

Going back to our starting point on the European gender mainstreaming approach, our take is that, indeed, this policy framework has acknowledged the key contribution of work-life reconciliation as an important input for human development. Yet, human development thrives on 
social cohesion and economic growth (Ranis et al. 2005), which continuously reshape work-life reconciliation patterns at a higher efficiency equilibrium development path. 
Tab. 3 - Dimensions of Work-Life Reconciliation across Employment, Development, and Welfare Policies Throughout Italian Objective 1 Regions

\begin{tabular}{|c|c|c|c|c|c|c|}
\hline $\begin{array}{l}\text { Work-life } \\
\text { reconciliation } \\
\text { policies }\end{array}$ & Contexts & $\begin{array}{l}\text { Within gender } \\
\text { heterogeneity }\end{array}$ & Human development & $\begin{array}{l}\text { Culture } \\
\text { Social capital }\end{array}$ & Inter-temporal welfare & Economic growth \\
\hline $\begin{array}{l}\text { Art. 9, Law n. } \\
53 / 2000\end{array}$ & Nation-wide & $\begin{array}{l}\text { Increasing the range of } \\
\text { choices and capabilities }\end{array}$ & $\begin{array}{l}\text { Individual- } \\
\text { households } \\
\text { aspirations realization }\end{array}$ & $\begin{array}{l}\text { Household-community } \\
\text { needs care } \\
\text { Poverty trap }\end{array}$ & $\begin{array}{l}\text { Social beliefs } \\
\text { transmission } \\
\text { Quantity-quality time } \\
\text { Path dependency }\end{array}$ & $\begin{array}{l}\text { Higher allocative } \\
\text { efficiency }\end{array}$ \\
\hline $\begin{array}{l}\text { European Lisbon } \\
\text { Strategy Measure } \\
\text { E1 of European } \\
\text { Cohesion Policy }\end{array}$ & $\begin{array}{l}\text { European Union- } \\
\text { wide }\end{array}$ & Entitlement & $\begin{array}{l}\text { Equal opportunities } \\
\text { between men and } \\
\text { women }\end{array}$ & Human rights & $\begin{array}{l}\text { Human rights across } \\
\text { generations }\end{array}$ & $\begin{array}{l}\text { Balance between } \\
\text { production and } \\
\text { distribution of income }\end{array}$ \\
\hline Job creation & $\begin{array}{l}\text { Italian Objective } 1 \\
\text { Areas (measure } 3.14 \\
\text { of Regional } \\
\text { Operational } \\
\text { Programs) }\end{array}$ & $\begin{array}{l}\text { Increasing the range of } \\
\text { choices Trade-off } \\
\text { between paid and } \\
\text { unpaid work }\end{array}$ & $\begin{array}{l}\text { Labor and managerial } \\
\text { skills } \\
\text { Professional growth } \\
\text { Less time for } \\
\text { household and } \\
\text { community care }\end{array}$ & $\begin{array}{l}\text { Modern vs. traditional } \\
\text { female roles in society } \\
\text { Trade-off between } \\
\text { Work vs. care/leisure } \\
\text { Competing on the job } \\
\text { market vs. reciprocity } \\
\text { and social ties }\end{array}$ & $\begin{array}{l}\text { Greater opportunities } \\
\text { for children } \\
\text { Decreased poverty } \\
\text { Trade-offs between } \\
\text { individualistic vs. } \\
\text { solidaristic society }\end{array}$ & $\begin{array}{l}\text { Increased income } \\
\text { (GDP) } \\
\text { Increased public and } \\
\text { household expenditure }\end{array}$ \\
\hline $\begin{array}{l}\text { Female business } \\
\text { start-ups }\end{array}$ & $\begin{array}{l}\text { Italian Objective } 1 \\
\text { Areas (Regional Law } \\
215 \text { in Campania) }\end{array}$ & $\begin{array}{l}\text { Increasing the range of } \\
\text { choices and capabilities }\end{array}$ & Entrepreneurial skills & $\begin{array}{l}\text { Economic } \\
\text { opportunities' growth } \\
\text { Stiffer competition } \\
\text { Less cooperation }\end{array}$ & $\begin{array}{l}\text { Increasing income and } \\
\text { decreasing poverty rates }\end{array}$ & Greater competitiveness \\
\hline $\begin{array}{l}\text { Vocational } \\
\text { training }\end{array}$ & $\begin{array}{l}\text { Italian Objective } 1 \\
\text { Areas }\end{array}$ & $\begin{array}{l}\text { Increasing the range of } \\
\text { capabilities }\end{array}$ & $\begin{array}{l}\text { Higher labor and } \\
\text { managerial skills } \\
\text { Employability }\end{array}$ & $\begin{array}{l}\text { More training in } \\
\text { science and technology } \\
\text { vs. humanity studies } \\
\text { Possible loss of cultural } \\
\text { heritage }\end{array}$ & $\begin{array}{l}\text { Higher percentages of } \\
\text { scientists and } \\
\text { technicians }\end{array}$ & $\begin{array}{l}\text { More efficient job } \\
\text { market } \\
\text { Cultural identity? }\end{array}$ \\
\hline Welfare services & $\begin{array}{l}\text { Nation-wide } \\
\text { Subregional-zone } \\
\text { plans }\end{array}$ & $\begin{array}{l}\text { Increasing the range of } \\
\text { capabibilities }\end{array}$ & $\begin{array}{l}\text { Physical, mental, } \\
\text { household welfare }\end{array}$ & $\begin{array}{l}\text { Social welfare } \\
\text { Addressing inequalities } \\
\text { Income distribution } \\
\text { consumption vs. } \\
\text { savings }\end{array}$ & $\begin{array}{l}\text { Increasing life } \\
\text { expectancy and literacy } \\
\text { rates } \\
\text { Child welfare }\end{array}$ & $\begin{array}{l}\text { Increasing quality of } \\
\text { life } \\
\text { Distribution of higher } \\
\text { income }\end{array}$ \\
\hline
\end{tabular}




\section{Appendix}

\section{Policies for equal opportunities - Work-life reconciliation - Regional Development}

\section{A. Reconciliation and cross-gender difference}

What motivations underlie positive actions in favour of women, which have been undertaken by Campania Region over the 2000-2006 programming cycle?

a. Limited access to labour market

b. Discrimination, segregation, and salary differentials

c. Differences in education levels

d. Women limited presence in R\&D activities

e. Support to caring labour (not paid)

f. Limited participation in collective action

\section{B. Reconciliation and within-gender difference}

What within-gender differences are considered to be crucial within gender friendly policies adopted by Campania Region over the 2000-2006 programming cycle?

a. Age difference

b. Differences in education levels

c. Income disparities

d. Differences in employment sectors (services, manufacturing, agricolture)

e. Differences in employment forms (part-time, full-time, flexible working arrangements)

f. Differences in working positions and roles (white collars, blu collars, mangers, self-employed, entrepremeurs) Differences in family composition

g. Differences in socioeconomic and family status

h. Differences in preferences between paid and unpaid work

\section{Reconciliation and family}

In what ways Campania Region's policy measures promote work-life reconciliation within family?
a. Flexible working time
b. Alignment of commercial services time
c. Public transportation supply for reducing commuting times (work, home)
d. Entry-job opportunities
e. Regularization of informal working positions
f. Opportunties for career progression
g. Opportunties for professional growth through training
h. Promotion of leadership and managerial skilss
i. Adeguate supplì of care services (childcare, elderly and disabled support)
j. $\quad$ Parenting support
k. Promotion of cultural and sport activities
l. Promotion of participation in collective action

What change mechanisms are activated by Campania Region's gender friendly policies that promote work-life reconciliation, influencing individual and family preferences and choices?
a. Change/increase in individual aspirations
b. Alterino power relations and structures within couple/family
c. Recognition of cultural values in favour of role and responsibilities sharing
d. Stigmatization and social sanction of gender discrimination
e. Appreciation of intergenerational and intertermporal choices (i.e., saving for children education, asset building)
f. Reduction of perceived future uncertainty
g. Propensitiy for family investments 


\section{Reconciliation and economic development}

In what ways work-life reconciliation measures promote regional development?
a. Personal emancipation/human development
b. Education and professional training as requested by labour markets needs
c. Creation/regularization of working positions for women across non segregated sectors
d. Creation/regularization of sustainable firms on local/regional/international markets
e. Broader access to credit
f. Socioeconomic partnership development (social cooperation, social responsibility)
g. Institutional partnership development (reform of social services at the local level in response to needs)

What social and economic mechanisms activated by gender friendly policies promote regional development?
a. Broadening of opportunities and production/income choices
b. Agglomeration effects
c. Overcoming inequalities and social disparities
d. Codified and tacit knowledge spill-pover effects
e. Increase in cooperation and trust
f. Creation and consolidation of formal institutions
g. Strengthening enforcement for contracts
h. Consolidation of participatory democracy
i. Improvement of economic performance (increase in per capita GDP) 
Formal testing

1. In light of various training modules on Gender equality, please, elaborate on the idea of Equal Opportunities

2. What aspects of "women conditions" are relevant in the various dimensions of your own life experience (professional, familial, relational, personal)? How would you define your own condition vis-à-vis the persons you frequently interact with (specify if men or women)?What is and how do you perceive your role across different contexts of interaction?

3. What is your idea about the problem of work-life reconciliation? In what ways have you modified your original idea during the course? What is your direct and indirect experience of reconciliation of work and private life (within family, on the job, within relationships) Qual è la sua idea del problema della conciliazione dei temi?

4. What are your aspirations? To what extent do you think you have fulfilled your aspirations? What do you think you need yet to fulfil your aspirations? How has this course contributed to changing your aspirations (readings, case studies, comparison with similar or different experiences, role models) 
ADDIS, E. (2002) “Gender symmetry in the Reform of European welfare state,” European University Institute Working Paper, Florence.

ADSERA' A. and RAY D. (1998), "History and Coordination Failure”, Journal of Economic Growth, 3, 267-276

AGARWAL B. (1997),” Bargaining and Gender Relations: within and beyond the Household”, Feminist Economics, 3(1), 1-51

AGARWAL B. (2002), Gender Inequality, Cooperation and Environmental Sustainability”, Institute of Economic Growth, Dehli, mimeo

AGARWAL B. (2004), “Feminist Economics as a Challenge to MainstreaM economics?”, IAFFE Newsletter, 14 (3)

AOKI M. (2007), “Endogenizing Institutions and Institutional Changes”, Journal of Institutional Economics, 3(1), 1-31

APPADURAI A. (2002), The Capacity to Aspire, in Rao V and Walton M eds, Culture and Public Action, The World Bank, Washington, 59-84

AZARIADIS C. (2006), The Theory of Poverty Traps. What Have We Lernead?, in Bowles S., Durlauf S.N., Hoff K. eds, Poverty Traps, Princeton University Press, Princeton, 17-40

AZARIADIS C. and DRAZEN A. (1990), "Threshold Externalities and Development

Economics”, Quarterly Journal of Economics, 105, 501-526

BALLET J., DUBOIS J-L. and MAHIEU F-R (2007),” Responsability foe Each Other's Freedom : Agency as the Source of Collective Capability”, Journal of Human Development, 8(2), 185-201

BANERJEE A. and DUFLO E. (2005), Growth Theory Through the Lens of Development Economics, in Durlauf S.N. and Aghion P., Handbook of Growth

Economics, Vol. 1A, Nort Holland, Amsterdam

BARKER D. (2003), “Emancipatory for Whom? A Comment on Critical Realism”, Feminist Economics, 9(1), 103-108

BARKER D. (2005), “ Beyond Women and Economics: Rereading “Women’s Work”, Journal of Women in Culture and Society, 30 (4), 2190-2209

BETTIO F., DEL BONO E. and SMITH M. (1998) "Working Time Patterns in the European Union: Policies and Innovations" Commission for the European Communities. [CE-V/2-98-010-EN-C].

BOSERUP E. (1970), Women's Role in Economic Development, Allen and Union, London

BOWLES S. (1998),” Endogenous Preferences: The Cultural Consequences of Markets

and other Economic Institutions”, Journal of Economic Literature, XXXVI, 75-111

BOWLES S. (2006), Institutional Poverty Traps, in Bowles S.et al., 116-138

BOWLES S., DURLAUF S. N. and HOFF K. eds (2006), Poverty Traps, Princeton

University Press, Princeton

BURGESS R. and VENABLES A. J. (2004) Toward a Microeconomics of Growth, Working Paper No. 3257, World Bank Policy Research, Washington

CARBONE J and CAHN N. (2005), " Behavioral biology, the Rational Actor Man, and New

Feminist Agenda”, George Washington University, Legal Studies Research Paper Series, no 276

CAROLEO F.E. and GAROFALO M.R. (2006), "Il modello sociale europeo: quale

opportunità di occupazione per il terzo settore?”, Impresa Sociale, 1, 27-56

CICCONE A. and MATSUYAMA K. (1996)," Start-up Costs and Pecuniary

Externalities as Barriers to Economic Development”, Journal of Development

Economics, 49, 33-59

CISCEL, D.H., HEATH, J.A. (2001) !To market, to market: imperial capitalism's destruction of social capital and the family," Review of Radical Political Economics, 33, 401-414.

DIXIT A. (1996), The Making of Economic Policy. A Transaction Costs Politics, The MIT Press, Cambridge 
DOPFER K., FOSTER J. and POTTS J (2004), Micro-Meso- Macro“, Journal of Evolutionary Economics, 14, 163-219

DREZE J, SEN A. (1995), India: Economic Development and Social Opportunity, Oxford

University Press, Oxford

DURLAUF S.N. (2006), Groups, Social Influences and Inequality: A Memberships

Theory Perspective on Poverty Traps, in Bowles S. et al., 141-175

EGGERTSSON T. (1998), Limits to Institutional Reform, Scandinavian Journal of

Economics, 100, 335-357

ELSON, D., PEARSON, R. (1981) "The subordination of women and the internationalization of factory production, in K. Young et al. eds. Of marriage and the market: women's subordination in international perspective, London: CSE Books.

EUROPEAN COMMISSION (1999), "Employment Policies in the European Union and in the State Members", Bruxelles

FOLBRE A. and NELSON J. (2002), For Love and for Money, Journal of Economic Perspectives, 4, 123-140.

FONDAZIONE G. BRODOLINI (2007) Study on poverty and social exclusion among loneparents households, Rome.

GINTIS H., BOWLES S., BOYD R. and Fehr E. eds (2005) Moral Sentiments and Material interests: the Foundations of Cooperation in Economic Life, The MIT Press, Cambridge HARDING S: (1999), “The Case for Strategic Realism: A Response to Lawson”, Feminist Economics, 5(3), 127-133

HERTZ, R. (1997) "A typology of approaches to childcare: The centrepiece of organizing family and life for dual-earner couples,” Journal of Family Issues, 18, 355-385.

HILL M. (2007), "Confronting Power through Policy: on the Creation and Spread of Liberating Knowledge,” Journal of Human Development, 8(2), 259-282

HIRSHMAN A. (1958), The Strategy of Economic Development, Yale University Press, New

Haven

HOFF K. (2000), "Beyond Rosenstein Rodan: The Modern Theory of Coordination

Problems in Development,” Annual Bank Conference on Development Economics, The World Bank, 145-176

HOFF K., SEN A. (2006), The Kin System As a Poverty Trap, in Bowles S. et al.,95-115

ISFOL (2004) Conciliazione tra vita lavorativa e vita familiare, integrazione delle politiche $e$ problemi di valutazione, Unità Pari Opportunità, Roma

ISTAT (2005) Avere un figlio, Rome.

ISTAT (2005) Essere madri oggi, Rome.

JACKSON, C. (2001) "Rescuing Gender From the Poverty Trap.” Review of Radical Political Economics, 33, 495-508.

JHA S. (2004), Cultured Economic Theory: Oxymoron or incipient reality?, Standford University, mimeo

LAWSON T. (1999), "Feminism, Realism and Universalism”, Feminist Economics, 5(2), 25-59

LAWSON T. (2003),”Ontology and Feminist Theorizing”, Feminist Economics, 9(1), 119-50

LITTON, FOX, G., MCBRIDE MURRY, V. (2000) "Gender and Families: A Feminist

Perspective,” Journal of Marriage and the Family, Vol. 62, No. 4, 160-1172.

MANSDOTTER, A., LINDBLOM, L., WINKVIST, A. (2007) "Parental leave in Sweden - Cost savings and health gains, Health Policy, 82, 102-115.

MARKS, N.F. (1998) "Does it hurt to care? Caregiving, work-family conflict, and midlife wellbeing,” Journal of Marriage and the Family, 60, 951-966.

MARRA, M. (2004) "Strumenti di emersione e meccanismi di cambiamento" in Stame, N. (2004)

Per la valutazione della politica di emersione, Franco Angeli, Milano pp. 77-104.

MATSUYAMA K. (1996), Economic Development as Coordination Problems, in M. Aoki, H.

Kim, M. Okuno Fujwara eds, The Role of Government in East Asian Development, Oxford

University Press, Oxford, 134-159 
MEIER G., STIGLITZ J. E. eds (2004), Frontiers of Development Economics, Oxford University Press, Oxford

MELDOLESI, L. (2003) “La politica dell'emersione dell'economia e del lavoro irregolari”, Economia Italiana, n.1.

MELDOLESI, L., MARCHESE, M. (2005) Emersione al femminile, Carocci, Roma.

MIKKOLA A. (2005), "Role of Gender Equality in Development. A Review Literature”, Dpt. Of Economics, University of Helsinki, mimeo

MUTARI, E. (2001) “...As broad as our life experience”: visions of feminist political economy, 1972-1991,” Review of Radical Political Economics, 33, 379-399

NELSON J. (2003), “Once More, with Feeling: Feminist Economics and the Ontological

Questions”, Feminist Economics, 9(1), 109-118

NELSON J. (2004), "Freedom, Reason, and More: Feminist Economics and Human Development", Journal of Human Development, 5 (3), 309-333

NORTH D.C. (1990) Institutions, Institutional Change and Economic Performance, Cambridge University Press, Cambridge

NORTH D.C. (2005), Understanding the Process of Economic Change, Cambridge, Cambridge University Press

ORLOFF, A. (1996) Gender and the welfare state, Discussion Paper, Institute for Research on Poverty, University of Wisconsin-Madison, US.

PETER F. (2003), “ Critical Realism, Feminist Episemology , and the Emancipatory Potential of Science: a Comment on Lawson and Harding”, Feminist Economics, 9(1), 93-101

RANIS G., BOOZER M, STEWART F. and SURI T. (2003), Paths to Success: The Realationship between Human Development and Economic Growth, Economic Growth Center, Yale University, Disc. Pap. No.874

RANIS G:, STEWART F, SAMMAN E. (2005), Human Development:Beyond HDI, Economic Growth Center, Yale University, Disc. Pap. No. 916

RAY D. (1998), Development Economics, Princeton University Press, Princeton

RAY D. (2002), Aspirations, Poverty and Economic Change, New York and Institute de Analisis Economica (CSIC), mimeo

RAY D. (2000), “What’s New in Development Economics?”, The American Economist, 44,3-16

ROBEYNS I. (2000), Is there a Feminist Methodology?, Wolfson College, Cambridge UK, mimeo ROBEYNS I. (2003), “Sen’s Capability Approach and Gender Inequality: Selecting Relevant Capabilities”, Feminist Economics, 9 (2/3), 61-92

RUBERY J., FAGAN C., GRIMSHAW D., FIGUEIREDO H. and SMITH M. (2002), Indicators of Gender Equality in the European Employment Strategy, European Work and Emplyment Research Centre, Manchester School of Management, University of Manchester Institute of Science and Techonology

PAWSON, R., TILLEY, N. (1997), Realist Evaluation, London: Sage Publications. PAWSON, R. (2001) Evidence Based Policy: II. The Promise of 'Realist Synthesis, ESRC UK Centre for Evidence Based Policy and Practice, Working Paper 4, University of London, London. SARTORI D. (2005), ...Et Dona Ferentes. La Dichiarazione dei Diritti del 1789, un Dono Doppio, in Giacomin B. and Che motti S. eds, Donne in Filosofia, Il Poligrafo, Padova, 89-107 SCHMID G. and SCHONMANN K (1995), “Institutional Choice and Flexible Coordination. A Socio-Economic Evaluation of Labour Market Policy in Europe”, in Schimd G. et al. eds, Labour Market Institutions in Europe, London, M. E. Sharpe

SEN A. (1999), Development as Freedom, Albert A. Knopf, New York

SEN A. (2003),"'Continuing the Conversation”,Feminist Economics, 9 (2/3), 319-332

SIMONAZZI A. ed., (2006), Questioni di Genere, Questioni di Politica, Ed. Carocci, Rpma VILLA P. (2006), Famiglia, Impresa e Società: gli Effetti delle Politiche di Conciliazione, in Simonazzi A. ed., Roma, 63-89 
WITT U. (2003), “Economic Policy Making in Evolutionary Perspective”, Journal of Evolutionary Economics, 13, 77-94 